\title{
Complement-Related Proteins and Their Measurements: The Current Status of Clinical Investigation
}

\author{
Katsuki Ohtani \\ Department of Food Science and Human Wellness, Rakuno Gakuen University, Ebetsu, Japan
}

\section{Keywords}

Complement $\cdot$ Complement-related factors $\cdot$ Clinical examination · Complement-related diseases · Genetic abnormalities

\begin{abstract}
Complement has been considered to be a factor that protects the host against invading microorganisms during infection. However, in recent years, complement-related protein deficiency has been found to be involved in the onset of various diseases, such as autoimmune and inflammatory diseases. In Japan, C3, C4, and CH50 tests were generally performed only when a complement system examination was necessary and there were not enough examinations for other complement factors. Since the complement system has a very complicated activation pathway, at present, it is not well known which molecule must be measured to understand the pathological condition or pathogenesis in complement-related diseases. Furthermore, since the frequency of complement factor gene alleles also differs depending on race, data from foreign countries cannot be directly applied to Japanese populations. Under these circumstances, the
\end{abstract}

Japanese Association for Complement Research (JACR) has prepared approximately 20 items for complement-related examinations, including the 5 categories of functional analysis, complement factors, complement regulators, activation products, and autoantibodies.

(c) 2020 S. Karger AG, Basel

\section{Complement Factors and the Complement System}

Complement was discovered as a serum protein system that assists the action of antibodies, and this system is currently known to include the main components of complement ( $\mathrm{C} 1$ to $\mathrm{C} 9$ ) and other complement-related molecules (factor B and factor D). There are 8 types of humoral regulatory factors (complement factor I [CFI], complement factor $\mathrm{H}[\mathrm{CFH}], \mathrm{C} 4$ binding protein, $\mathrm{C} 1 \mathrm{in}-$ hibitor [C1-INH], properdin, C3a/C5a inhibitor, S protein, and clusterin) [1], 4 cell membrane proteins (CR1, MCP [CD46], DAF [CD55], and CD59) [2,3], and 7 complement receptors $(\mathrm{C} 1 \mathrm{qR}, \mathrm{C} 3 \mathrm{aR}, \mathrm{C} 5 \mathrm{aR}, \mathrm{CR} 1, \mathrm{CR} 2, \mathrm{CR} 3$, and CR4) [4]. Together, all proteins and their functions constitute the complement system.

$\begin{aligned} & \text { karger@karger.com } \\ & \text { www.karger.com/nef }\end{aligned}$
Karger ${ }^{\prime /}$


Fig. 1. Activation pathway of the complement system and target factors for standardization of complement-related examination. $\mathrm{CP}$, classical pathway; AP, alternative pathway; LP, lectin pathway; TCC, terminal complement complex; CFI, complement factor I; CFH, complement factor $\mathrm{H}$; C1-INH, C1 inhibitor.

Table 1. Examination system for complement-related proteins

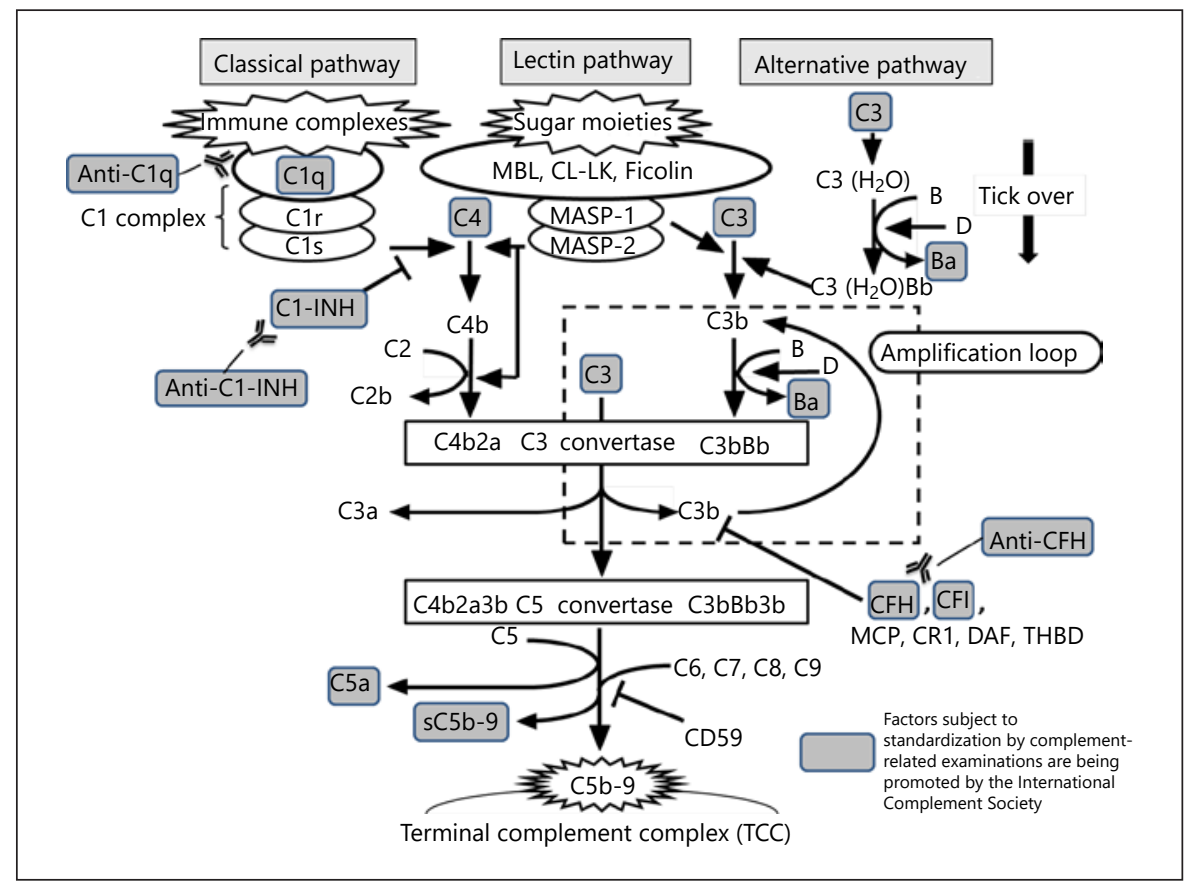

\begin{tabular}{|c|c|}
\hline & Examination items \\
\hline Functions & $\underline{\mathrm{CH} 50}, \mathrm{ACH} 50, \mathrm{LP}$ activity \\
\hline Components & $\underline{\mathrm{C} 3}, \underline{\mathrm{C}} 4, \mathrm{C} 1 \mathrm{q}$ \\
\hline Regulators & $\underline{\mathrm{CFH}}, \underline{\mathrm{CFI}}, \underline{\mathrm{C} 1-\mathrm{INH}}$ (activity and protein) \\
\hline Activation products & $\mathrm{C} 3 \mathrm{dg}, \mathrm{C} 3 \mathrm{a}, \mathrm{Bb}(\underline{\mathrm{Ba}}), \underline{\mathrm{sC} 5 \mathrm{~b}-9},(\underline{\mathrm{C} 5 \mathrm{a}})$ \\
\hline Autoantibodies & Anti-C1q, anti-C1-INH (IgG/A/M), anti-CFH, C3Nef \\
\hline \multicolumn{2}{|c|}{$\begin{array}{l}\text { LP, lectin pathway; CFH, complement factor } \mathrm{H} \text {; CFI, complement factor I; C3Nef, C3 } \\
\text { nephritic factor; C1-INH, C1 inhibitor. Underlined items are measured by the JACR at } \\
\text { present. Twenty testing items to be standardized worldwide }\end{array}$} \\
\hline
\end{tabular}

\section{Current Status of Measurement for Complement Abnormalities}

Until recently, in Japan, special examinations for complement have been carried out by some groups from the Japanese Association for Complement Research (JACR) as volunteers [5]. Complement factor deficiencies are known to differ significantly depending on race, but there is not much specific information on the gene mutation frequencies of the complement regulatory factors in the Japanese population.

The JACR discussed a reconstruction of new complement examinations under the initiative of an academic society, "Comprehensive registration of complement-related diseases and establishment of treatment guidelines by building a new complement examination system" $[6$,
7]. This strategy was determined at the JACR board meeting. The examinations are divided into 2 parts: (1) complement factor and complement function analyses and (2) complement-related genetic analyses, mainly using blood. The current status and significance of each examination are outlined.

\section{Complement Factors and Their Functional Analyses}

Currently, in Japan, C3, C4, and CH50 are commonly measured when they are required for clinical evaluation. Until now, these 3 factors have been regarded as sufficient for complement examinations. However, these measurements cannot detect subtle and local complement activation in complement-related diseases. The activation path- 
way of the complement system (shown in Fig. 1) is very complicated, and unfortunately, at the present time, which factor analysis is appropriate for understanding the pathophysiology and which factor participates in the pathogenesis of complement-related diseases have not been fully determined. Moreover, since the allele frequencies of complement genes vary depending on race, the genomic characteristics in foreign countries cannot be directly applied to the Japanese population.

Under these circumstances, the International Complement Society (ICS) classified the complement examination items into 5 categories (functional analysis, complement factors, complement regulators, activation products, and autoantibodies) (Table 1) for the purpose of standardization of complement examinations and recommended that each member of society undergo approximately 20 complement-related examinations [8-10].

\section{Functional Analysis: CH50, ACH50, and Lectin Pathway Analysis}

There are 3 pathways in complement activation. First, a classical pathway (CP) is initiated by the formation of an antigen-antibody complex and its binding to C1q. Second, a lectin pathway (LP) is triggered by pattern recognition of a sugar chain by a lectin. Third, there is an alternative pathway (AP) in which activation is constantly occurring at a low level by hydrolysis $[2,11]$. The AP is thought to play an important role as an amplification pathway of complement activation initiated by the $\mathrm{CP}$ and the LP. To measure the $\mathrm{CP}, \mathrm{CH} 50$ is performed by observing hemolysis of sensitized erythrocytes by complements in a sample, and to measure AP, ACH50 is performed by observing hemolysis of rabbit erythrocytes $[12,13]$. The CP requires calcium and magnesium ions, whereas the AP does not require calcium ions; therefore, the use of Mg-EGTA buffer can prevent hemolysis due to the $\mathrm{CP}$. There are also ELISA kits that can measure the activation of the 3 pathways individually. For the CP, LP, and AP assays, samples are placed in IgM-, mannan-, and LPS-coated wells, respectively, activated by complement factors in the samples, and evaluated by detection of C5b-9 formation [14].

\section{Complement Factors: C3, C4, and C1q}

In addition to the functional analysis mentioned above, measuring the protein concentrations of $\mathrm{C} 3, \mathrm{C} 4$, and $\mathrm{Clq}$ makes it possible to infer in which pathway and why abnormal complement activation is occurring in more detail.

In Japan, there was a period when all C1-C9 proteins were quantitatively measured previously, but now there

Complement and Their Measurements are some negative opinions regarding the measurement of mere complement factors. For example, in atypical hemolytic uremic syndrome (aHUS), abnormal complement activation is involved locally, and the values of $\mathrm{C} 3$, $\mathrm{C} 4$, and $\mathrm{CH} 50$ are not markedly changed [15-17].

\section{Complement Regulators: CFH, CFI, and C1-INH}

(Activity and Protein)

Liquid phase regulators in complement activation include $\mathrm{CFH}, \mathrm{CFI}$, and $\mathrm{C1}-\mathrm{INH}$. $\mathrm{CFH}$, which is present at high concentrations $(500 \mu \mathrm{g} / \mathrm{mL})$ in plasma, works in both the liquid and solid phases and attenuates the activity of $\mathrm{C} 3$ convertase in the alternative pathway and acts as a cofactor for factor I cleave C3b and C4b [18]. It is a multifunctional molecule that has the function of decay acceleration and plays a very important role in regulating complement activation. $\mathrm{C} 1$-INH binds to $\mathrm{C} 1 \mathrm{r}, \mathrm{C} 1 \mathrm{~s}$, and mannose-binding lectin-associated serine proteases (MASP)-1, MASP-2, and MASP-3 in the liquid phase, inhibits the serine protease activity of these proteins, and controls the activation of the CP and the LP [19-21]. The activity of C1-INH is mainly examined, and quantification is performed when examining the disease type in more detail. Quantitating the protein levels of the complement regulatory factors is a sufficiently useful test in cases of complete loss of regulatory factors, but there are many genetic mutations with which the decrease in regulatory factor protein concentration is not significant $[22$, 23].

\section{Activation Products: $C 3 d g, C 3 a, B b(B a), s C 5 b-9$, and} C5a

Activation products comprise $\mathrm{C} 3 \mathrm{dg}, \mathrm{C} 3 \mathrm{a}, \mathrm{Bb}(\mathrm{Ba})$, sC5b-9, and C5a and can be detected as complement activation in vivo in a sensitive manner. Their measurement is clearly important because C3a and C5a act as strong anaphylatoxins [24], and $\mathrm{Bb}(\mathrm{Ba})$ and sC5b-9 in blood indicate the results of complement activation in vivo [25]. The measurement of the complement activation degradation product is reasonable and is currently the most attractive strategy to explore. Particularly useful activation products for aHUS include $\mathrm{Bb}(\mathrm{Ba}), \mathrm{C} 5 \mathrm{a}$, and sC5b-9, suggesting a transition to terminal complement complex formation $[17,26,27]$.

\section{Autoantibodies: Anti-C1q, anti-C1-INH (G/A/M), anti-CFH, and C3 Nephritic Factor}

In addition, autoantibodies to complement factors are associated with the onset of complement-related disease and are listed as measurement items. Anti-C1q antibody 
Fig. 2. Targets of complement gene testing (115 complement-related genes + diseaserelated genes). $\mathrm{CP}$, classical pathway; AP, alternative pathway; LP, lectin pathway.

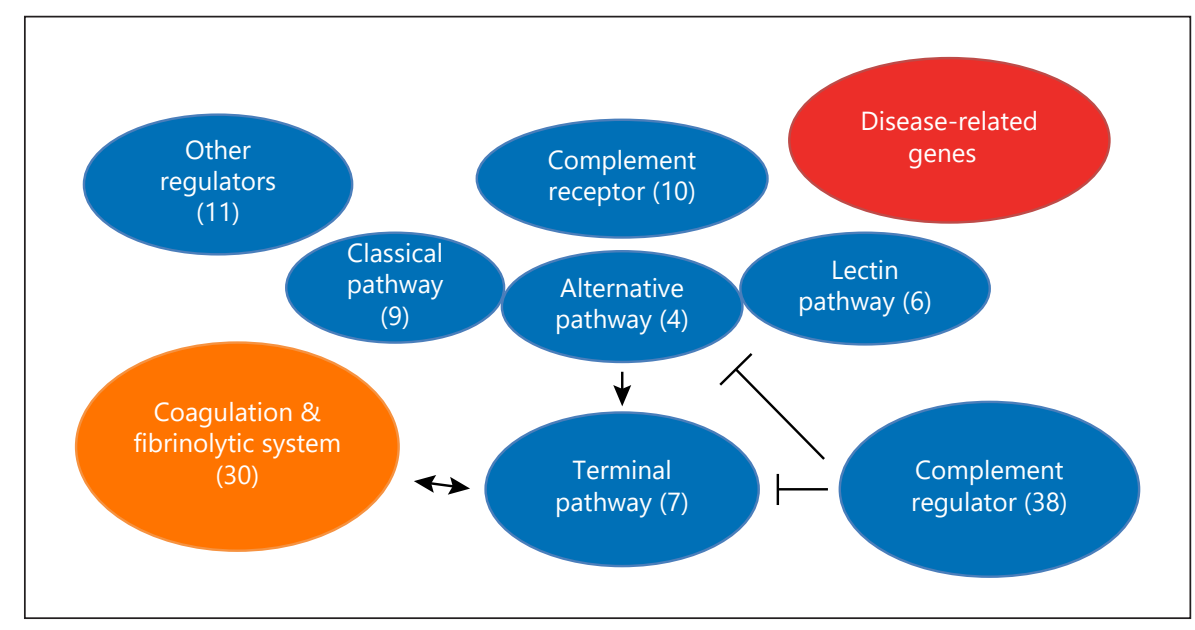

causes systemic lupus erythematosus [28], anti-Cl-INH antibody causes hereditary angioedema $[29,30]$, anti-FH antibody causes aHUS [31, 32], and C3 nephritic factor stabilizes $\mathrm{C} 3$ convertase and activates complement due to C3 glomerulopathy [33-35]. When the level of autoantibodies to complement regulatory factors increases, the complement regulation system may malfunction, and thus complement activation may proceed. In the future, more autoantibodies to complement factors will be identified in association with some complement-related diseases of unknown etiologies.

Under these circumstances mentioned above, the JACR developed the following 11 items divided into the 5 categories proposed by ICS: (1) CH50; (2) C3, C4; (3) $\mathrm{CFH}, \mathrm{CFI}$, and C1-INH (activity and protein); (4) Ba, sC5b-9, and C5a; and (5) anti-CFH during the 3 years after 2015 and is now planning to prepare all 20 items recommended by ICS step by step.

\section{Genetic Abnormalities in Complement Factors and Their Regulators}

In addition to aHUS [36], age-related macular degeneration [37] and C3 glomerulopathy [38-40] are included as examples of the complement-related diseases described above. Genetic abnormalities have been identified and reported [41-46]. However, there are many complementrelated diseases in the following fields: pediatrics, nephrology, hematology, neurology, ophthalmology, dermatology, and transplantation [47]. We believe that it is important to conduct complement gene research led by the JACR. In complement-related diseases, we analyzed 115 genes, including complement-related genes (85 genes) and coagulation/fibrinolytic system-related genes, as well as previously reported gene abnormalities (shown in Fig. 2). In the case of suspected hereditary angioedema, 136 genes, including 21 related genes, were further analyzed [48]. As a method, targeted exome sequencing of these complement-related genes was performed using next-generation sequencing. For data analysis, variation frequency analysis was performed with reference data from the Human Genetic Variation Database (Kyoto University) [49] and Exome Aggregation Consortium [50]. For genetic variation and disease data, the Human Gene Mutation Database was used [51, 52]. In addition, we are conducting some analytical studies on genetic variation and complement function using programs that predict three-dimensional structures. In addition, the genes that are thought to be particularly involved in aHUS (CFH, MCP, CFI, C3, CFB, THBD, PLG, and DGKE) are being reexamined using Sanger sequencing as another gene analysis method to supplement the next-generation sequencing system. Although important information can be obtained from genetic analysis for the current complement-related diseases, it is extremely difficult to determine the pathological significance of the genetic variations by only genomic information.

\section{Global Standardization of Complement Analyses and Future Prospects}

The methods of complement measurement include ELISA and the other testing systems using commercially available or noncommercial kits, and the protocols of the tests are different, making it difficult to compare the results from different laboratories. Strict complement test- 
ing requires even more caution (usually complement test samples are required to be frozen as soon as possible and transported on dry ice). In particular, the measurement of complement activation degradation products is very difficult because complement is rapidly activated at room temperature. For these reasons, we consider it to be important to transport the samples to the JACR center laboratory with the utmost caution and to establish an intensive complement testing system.

In January 2016, the External Meeting on the Standardization of Complement Measurements was held in Budapest, Hungary. The meeting presented the lessons from External Quality Assessments (EQAs) 1-5, which were discussed during the 5 years from 2010 to 2015 , and the results of EQA5 [53, 54]. Subsequently, EQA6/2016 was performed in October 2016. In EQA6/2016, the participants from each country registered the test items with INSTAND (An interdisciplinary, not-for-profit, scientific medical society, 1 of 3 reference institutions appointed by the German Medical Association and thus responsible for the organization of EQAs for quality control in medical laboratories), sent the test samples, and reported the measurement values. If each test result fell within the range of the reference value, a certificate was issued indicating that the result of the evaluation was valid. The JACR also participated in EQA6/2016 and received a certificate of validity for the quantitative tests for $\mathrm{C} 3, \mathrm{C} 4$, $\mathrm{CH} 50$, and sC5b-9 and for a qualitative test for anti-CFH.
Furthermore, as a future complement protein test, we believe that a batch complement test using the multiplex system (Luminex) or a similar system is a possible candidate for future investigations. The advantage of the multiplex system is that multiple complement factors in the blood can be simultaneously quantified. Cytokines are also used as a quantitative and reproducible technique for complement-related disease, but at present, their measurement is in the research stage. Furthermore, each parameter is currently being evaluated with the overall pattern of all test values. That is, the test value pattern of a type of complement-related disease is obtained and can be used for the diagnosis of complement-related diseases. This is beyond the scope of this review, but it can indicate future prospects if a certain trend is present in each disease. The JACR believes that the global standardization of complement measurements and a multiplex test system will provide a scientific contribution for complement research and clinical benefits for complement-related diseases.

\section{Conflict of Interest Statement}

The authors have no conflicts of interest to declare.

\section{References}

1 Zipfel PF, Skerka C. Complement regulators and inhibitory proteins. Nat Rev Immunol. 2009 Oct;9(10):729-40.

2 Nesargikar PN, Spiller B, Chavez R. The complement system: history, pathways, cascade and inhibitors. Eur J Microbiol Immunol (Bp). 2012 Jun;2(2):103-11.

3 Geller A, Yan J. The role of membrane bound complement regulatory proteins in tumor development and cancer immunotherapy. Front Immunol. 2019 May 21;10:1074.

4 Puri TS, Quigg RJ. The many effects of complement C3- and C5-binding proteins in renal injury. Semin Nephrol. 2007 May;27(3):32137.

5 Inai S, Kitamura H, Hiramatsu S, Nagaki K. Deficiency of the ninth component of complement in man. J Clin Lab Immunol. 1979 Apr;2(1):85-7.

6 Ohtani K, Inoue N, Hidaka Y, Wakamiya N. The analysis of complement factors and activation markers in normal Japanese individuals. Hotai. 2019;56(2):13-22.

7 Available from: http://square.umin.ac.jp/ compl/compl-examination/.
8 Prohaszka Z, Nilsson B, Frazer-Abel A, Kirschfink M. Complement analysis 2016: clinical indications, laboratory diagnostics and quality control. Immunobiology. 2016; 221(11):1247-58.

9 Brodszki N, Frazer-Abel A, Grumach AS, Kirschfink M, Litzman J, Perez E, et al. European Society for Immunodeficiencies (ESID) and European Reference Network on Rare Primary Immunodeficiency, Autoinflammatory and Autoimmune Diseases (ERN RITA) complement guideline: deficiencies, diagnosis, and management. J Clin Immunol. 2020 May;40(4):576-91.

10 Bergseth G, Ludviksen JK, Kirschfink M, Giclas PC, Nilsson B, Mollnes TE. An international serum standard for application in assays to detect human complement activation products. Mol Immunol. 2013 Dec;56(3): 232-9.

11 Ricklin D, Hajishengallis G, Yang K, Lambris JD. Complement: a key system for immune surveillance and homeostasis. Nat Immunol. 2010 Sep;11(9):785-97.
12 Nilsson B, Ekdahl KN. Complement diagnostics: concepts, indications, and practical guidelines. Clin Dev Immunol. 2012;2012: 962702.

13 Palarasah Y, Nielsen C, Sprogøe U, Christensen ML, Lillevang S, Madsen HO, et al. Novel assays to assess the functional capacity of the classical, the alternative and the lectin pathways of the complement system. Clin Exp Immunol. 2011;164(3):388-95.

14 Seelen MA, Roos A, Wieslander J, Mollnes TE, Sjöholm AG, Wurzner R, et al. Functional analysis of the classical, alternative, and $\mathrm{MBL}$ pathways of the complement system: standardization and validation of a simple ELISA. J Immunol Methods. 2005;296(1-2):187-98.

15 Kavanagh D, Goodship TH, Richards A. Atypical haemolytic uraemic syndrome. Br Med Bull. 2006;77-78:5-22.

16 Noris M, Caprioli J, Bresin E, Mossali C, Pianetti G, Gamba S, et al. Relative role of genetic complement abnormalities in sporadic and familial aHUS and their impact on clinical phenotype. Clin J Am Soc Nephrol. 2010 Oct;5(10):1844-59. 
17 Cataland SR, Holers VM, Geyer S, Yang S, Wu HM. Biomarkers of terminal complement activation confirm the diagnosis of aHUS and differentiate aHUS from TTP. Blood. 2014 Jun 12;123(24):3733-8.

18 Noris M, Remuzzi G. Overview of complement activation and regulation. Semin Nephrol. 2013 Nov;33(6):479-92.

19 Beinrohr L, Dobó J, Závodszky P, Gál P. C1, MBL-MASPs and C1-inhibitor: novel approaches for targeting complement-mediated inflammation. Trends Mol Med. 2008 Dec; 14(12):511-21.

20 Dobo J, Schroeder V, Jenny L, Cervenak L, Zavodszky P, Gal P. Multiple roles of complement MASP-1 at the interface of innate immune response and coagulation. Mol Immunol. 2014;61(2):69-78.

21 Garred P, Genster N, Pilely K, Bayarri-Olmos $\mathrm{R}$, Rosbjerg A, Ma YJ, et al. A journey through the lectin pathway of complement-MBL and beyond. Immunol Rev. 2016;274(1):74-97.

22 Germenis AE, Margaglione M, Pesquero JB, Farkas H, Cichon S, Csuka D, et al. International consensus on the use of genetics in the management of hereditary angioedema. J Allergy Clin Immunol Pract. 2020 Mar;8(3): 901-11.

23 Marcelino-Rodriguez I, Callero A, MendozaAlvarez A, Perez-Rodriguez E, Barrios-Recio J, Garcia-Robaina JC, et al. Bradykinin-mediated angioedema: An update of the genetic causes and the impact of genomics. Front Genet. 2019 Sep 27;10:900.

24 Klos A, Tenner AJ, Johswich KO, Ager RR, Reis ES, Köhl J. The role of the anaphylatoxins in health and disease. Mol Immunol. 2009 Sep;46(14):2753-66.

25 Wehling C, Kirschfink M. Tailored eculizumab regimen for patients with atypical hemolytic uremic syndrome: requirement for comprehensive complement analysis. J Thromb Haemost. 2014 Sep;12(9):1437-9.

26 Bu F, Meyer NC, Zhang Y, Borsa NG, Thomas C, Nester C, et al. Soluble c5b-9 as a biomarker for complement activation in atypical hemolytic uremic syndrome. Am J Kidney Dis. 2015;65(6):968-9.

27 Wehling C, Amon O, Bommer M, Hoppe B, Kentouche K, Schalk G, et al. Monitoring of complement activation biomarkers and eculizumab in complement-mediated renal disorders. Clin Exp Immunol. 2017;187(2):304-15.

28 Mahler M, van Schaarenburg RA, Trouw LA. Anti-C1q autoantibodies, novel tests, and clinical consequences. Front Immunol. 2013 May 14;4:117.
29 Varga L, Széplaki G, Visy B, Füst G, Harmat G, Miklós K, et al. C1-inhibitor (C1-INH) autoantibodies in hereditary angioedema. Strong correlation with the severity of disease in C1-INH concentrate naïve patients. Mol Immunol. 2007 Feb;44(6):1454-60.

30 Cugno M, Castelli R, Cicardi M. Angioedema due to acquired C1-inhibitordeficiency: a bridging condition between autoimmunity and lymphoproliferation. Autoimmun Rev. 2008 Dec;8(2):156-9.

31 Jozsi M, Licht C, Strobel S, Zipfel SL, Richter $\mathrm{H}$, Heinen $\mathrm{S}$, et al. Factor $\mathrm{H}$ autoantibodies in atypical hemolytic uremic syndrome correlate with CFHR1/CFHR3 deficiency. Blood. 2008 Feb 1;111(3):1512-4.

32 Blanc C, Togarsimalemath SK, Chauvet S, Le Quintrec M, Moulin B, Buchler M, et al. Antifactor $\mathrm{H}$ autoantibodies in $\mathrm{C} 3$ glomerulopathies and in atypical hemolytic uremic syndrome: one target, two diseases. J Immunol. 2015;194(11):5129-38.

33 Frémeaux-Bacchi V, Weiss L, Demouchy C, May A, Palomera S, Kazatchkine MD. Hypocomplementaemia of poststreptococcal acute glomerulonephritis is associated with $\mathrm{C} 3$ nephritic factor $(\mathrm{C} 3 \mathrm{NeF}) \mathrm{IgG}$ autoantibody activity. Nephrol Dial Transplant. 1994;9(12): 1747-50.

34 Zhang Y, Meyer NC, Wang K, Nishimura C, Frees $\mathrm{K}$, Jones $\mathrm{M}$, et al. Causes of alternative pathway dysregulation in dense deposit disease. Clin J Am Soc Nephrol. 2012 Feb;7(2): 265-74.

35 Zipfel PF, Skerka C, Chen Q, Wiech T, Goodship T, Johnson S, et al. The role of complement in C3 glomerulopathy. Mol Immunol. 2015 Sep;67(1):21-30.

36 Noris M, Mescia F, Remuzzi G. STEC-HUS, atypical HUS and TTP are all diseases of complement activation. Nat Rev Nephrol. 2012 Nov;8(11):622-33.

37 Park DH, Connor KM, Lambris JD. The challenges and promise of complement therapeutics for ocular diseases. Front Immunol. 2019 May 15;10:1007.

38 Fakhouri F, Frémeaux-Bacchi V, Noël LH, Cook HT, Pickering MC. C3 glomerulopathy: a new classification. Nat Rev Nephrol. 2010 Aug;6(8):494-9.

39 Pickering MC, D'Agati VD, Nester CM, Smith RJ, Haas M, Appel GB, et al. C3 glomerulopathy: consensus report. Kidney Int. 2013 Dec;84(6):1079-89.

40 Willows J, Brown M, Sheerin NS. The role of complement in kidney disease. Clin Med. 2020 Mar;20(2):156-60.
41 Haines JL, Hauser MA, Schmidt S, Scott WK, Olson LM, Gallins P, et al. Complement factor $\mathrm{H}$ variant increases the risk of age-related macular degeneration. Science. 2005 Apr 15; 308(5720):419-21.

42 Levy M, Halbwachs-MecarelliMecarelli LL Gubler MC, Kohout G, Bensenouci A, Niau$\operatorname{det} \mathrm{P}$, et al. $\mathrm{H}$ deficiency in two brothers with atypical dense intramembranous deposit disease. Kidney Int. 1986 Dec;30(6):949-56.

43 Fujisawa M, Kato H, Yoshida Y, Usui T, Takata M, Fujimoto M, et al. Clinical characteristics and genetic backgrounds of Japanese patients with atypical hemolytic uremic syndrome. Clin Exp Nephrol. 2018;22(5): 1088-99.

44 Loirat C, Fakhouri F, Ariceta G, Besbas N, Bitzan M, Bjerre A, et al. An international consensus approach to the management of atypical hemolytic uremic syndrome in children. Pediatr Nephrol. 2016;31(1):15-39.

45 Yoshida Y, Kato H, Ikeda Y, Nangaku M. Pathogenesis of atypical hemolytic uremic syndrome. J Atheroscler Thromb. 2019;26(2): 99-110.

46 Maugeri A, Barchitta M, Mazzone MG, Giuliano F, Agodi A. Complement system and age-related macular degeneration: Implications of gene-environment interaction for preventive and personalized medicine. Biomed Res Int. 2018 Aug 26;2018:7532507.

47 Ricklin D, Reis ES, Lambris JD. Complement in disease: a defence system turning offensive. Nat Rev Nephrol. 2016 Jul;12(7):383-401.

48 Csuka D, Veszeli N, Varga L, Prohászka Z Farkas $\mathrm{H}$. The role of the complement system in hereditary angioedema. Mol Immunol. 2017 Sep;89:59-68

49 Available from: http://www.hgvd.genome. med.kyoto-u.ac.jp/.

50 Available from: https://gnomad.broadinstitute.org/.

51 Stenson PD, Mort M, Ball EV, Evans K, Hayden M, Heywood S, et al. The Human Gene Mutation Database: towards a comprehensive repository of inherited mutation data for medical research, genetic diagnosis and next-generation sequencing studies. Hum Genet. 2017 Jun;136(6):665-77.

52 Available from: http://www.hgmd.cf.ac.uk.

53 Available from: https://www.complement. org/committee

54 Prohászka Z, Nilsson B, Frazer-Abel A, Kirschfink M. Complement analysis 2016: clinical indications, laboratory diagnostics and quality control. Immunobiology. 2016 Nov;221(11):1247-58. 